\title{
The Modern Trends and Applications in the Development of Academic Staff in the University of Maryland \& George Mason University
}

\author{
Alaa A. Asowayan ${ }^{1}$, Sammar Y. Ashreef ${ }^{1} \&$ Haya S. Aljasser ${ }^{1}$ \\ ${ }^{1}$ Curriculum \& Instruction Department $\mid K S U$, Ryiadh, KSA \\ Correspondence: Sammar Y. Ashreef, Curriculum \& Instruction Department|KSU, Ryiadh, KSA. E-mail: \\ softsnow345@gmail.com
}

Received: July 26, 2017 Accepted: September 9, 2017 Online Published: September 12, 2017

doi: 10.5539/elt.v10n10p102 URL: http://doi.org/10.5539/elt.v10n10p102

\begin{abstract}
Several changes have occurred over the past century in the education system of Saudi Arabia. The changes have largely been associated with the fact that in the 21 st century, information and communication technology is highly applied in the learning process, thereby leading to a major transformation of the process. The application of information and communication technology has also transformed interactions and rapidly changed the learning process, giving a new meaning to social interactions. Enterprises that operate in the information age enjoy information interchange, collaboration, and adoption and application of innovative tendencies and shared decision-making. Students' demands have changed in that they no longer hope for middle-class success or application of routine skills, but they measure success in terms of ability to share, communicate and apply information to arrive at solutions to complex problems. The changing learning environment requires that the teaching staff learns new tendencies and skills that they can apply to cope with the ever-changing learner and general society expectations. Teachers' competence at work is measured in terms of their ability to improve the power of technology in enhancing creation of new knowledge. Therefore, leaders of teacher education programs are responsible for developing sustainable programs that allow for teacher education. Training has become part of the ethics of the teaching profession, and members of the teaching staff must be ready for training throughout their profession. This paper will shed light on the training program of faculty members in two well-known universities in the United States: the University of Maryland \& George Mason University, as an attempt to compare the above educational establishments with the conditions of training of faculty members of King Saud University in Saudi Arabia to suggest a training plan to develop training programs in KSU. It is time when leaders in educator preparation should critically reexamine their roles in the 21 st century knowledge and skills whose landscape has largely changed.
\end{abstract}

Keywords: educators, technology, communication, collaboration, learning environment, knowledge, skills, transformation, innovation

\section{Introduction}

\subsection{The Modern Trends and Applications in the Development of Academic Staff in the 21st Century Skills}

Over the last century, a significant shift has been observed that focuses on information and knowledge service. According to American Association of Colleges for Teacher Education and the Partnership for 21st Century Skills (2010), the 21 st century is characterized by the application of information and communication technology that is rapidly transforming the learning process and the way people work, giving a new meaning to social relationships. Today's enterprises require that people share information, collaborate, display innovative tendencies and apply shared decision-making. In the learning set-up, students have stopped anticipating middle-class success or the application of ordinary skills to perform tasks that can be done by use of machines (American Association of Colleges for Teacher Education Committee on Innovation and Technology [AACTE], 2008). The situation has changed to the point that currently, success is largely dependent on the ability to share, communicate and apply information in solving complex problems. Success also lies in people's adaptive capacity and their level of innovativeness in response to the ever-changing situations and societal expectations. It 
is currently associated with people's ability to control and enhance the power of technology to facilitate creation of new knowledge (AACTE and the Partnership for 21st Century Skills, 2010).

It is important to recruit, train, reward and learn from talented academic staff to ensure that America remains competitive and to facilitate realization of America's dream of equal educational opportunity (AACTE Committee on Innovation and Technology, 2008). Education-based changes introduced in the 21 st century have currently made the role of academic staff more pronounced than it was a decade ago. Presently, teachers are required to acquire considerable academic growth for all students, while students' needs are becoming more advanced (AACTE and the Partnership for 21st Century Skills, 2010). The role of teachers has never been more important and the teaching process has never been more difficult than it is today. Diversity in learners' needs poses a lot of challenges to teachers such that they require thorough preparation to succeed in their service delivery. Learning institutions should check whether or not they have measures put in place to have their academic staff adequately prepared to win the critical battle. Thereafter, teacher educators must face the challenge. Moreover, learning institutions must be seen as exemplary educator training institutions. It is only possible if the institutions develop and implement changes that can enable them to respond to the modern trends and applications in the development of academic staff in the 21st century (Student Development Assessment Team, 2010).

The trends and applications in the development of academic staff in the 21 st century are analyzed with respect to current and future expectations of learners and the outcomes of the learning process (AACTE and the Partnership for 21st Century Skills, 2010). Academic staff has to apply modern trends in their tutoring to show that the basic skills competencies that were associated with the traditional learning process have been replaced by what learners should competently do. Today, institutions of learning ought to be committed to the transformation of their processes to ensure that the academic staff is endowed with collaborative and flexible problem-solving and innovative skills that will make them successful in their work. With reference to two American universities, namely the University of Maryland and George Mason University, this literature review presents an extensive analysis of the modern trends and applications in the development of academic staff in the 21 st century skills. From chapter three, the researchers will compare the above educational establishments with the conditions of training in King Saud University in Saudi Arabia to suggest a training plan to develop training programs in KSU (AACTE Committee on Innovation and Technology, 2008).

\subsection{Background Information about the University of Maryland}

The University of Maryland is located about 6.4 kilometers from the boarder of Washington, D.C on the northeast side. It is a research institution that is open to the general public which was founded in 1856 (Speck, 2010). The university's proximity to the capital of the nation makes it suitable for research partnership with the federal government. The University of Maryland provides "living learning" programs that give room for free interaction of students pursuing similar academic programs to live in the same residential community. An example of such residential community is the Honors College, which is meant to enable students to achieve their academic expectations as they live together and freely interact. The college comprises a high percentage of the institution's honors programs, and it allows learners to form a community of faculty and undergraduates (Speck, 2010).

The university's knowledge of and adaptability to the learning expectations of the 21 st century is evident in the way it gives room for the adoption of technology in the learning environment. For example, the Honors College has current programs such as digital culture and creativity and entrepreneurship and innovation that enable learners to acquire knowledge to face the 21st century challenges (AACTE Committee on Innovation and Technology, 2008).

Looking at the institution's action principles, it is committed to the formation of an inclusive community and adoption of technology in its processes. The institution also embraces partnership with the global community in addition to encouraging the entrepreneurial spirit in learners. The University of Maryland also gives learners the possibility to benefit from a wide range of support and success programs when they are outside the classroom. Most of the institution's programs justify that it is committed to inclusion and diversity, and that it allows for cross-cultural learning (Speck, 2010).

The management has to make efforts to ensure that the academic staff is adequately trained and motivated to handle the demands of the current educational environment. Hereby, they have to be equipped with skills that can enable them to handle learners from diverse cultural backgrounds. The reason is in the institution's commitment to facilitate effective global partnership. Moreover, there are adequate initiatives taken to facilitate distance learning due to the demands of such a platform in the 21 st century. The creation of virtual learning 
platforms by use of the World Wide Web has enabled the university to attract several distant learners who interact with their tutors through a variety of electronic platforms such as teleconferencing and by use of webinars. To make the programs effective, the management ensures that the academic staff is given regular training on the emerging technologies. Thereafter, such trainings facilitate provision of online tutoring and increase teachers' motivation and competence in offering technology-supported education services (Speck, 2010).

\subsection{George Mason University}

George Mason University is located in Faifax, and it is known to be the biggest public research university in the entire Commonwealth of Virginia (Broadwater, 2006). The institution was established in 1957 as a branch of the University of Virginia before it started functioning as an independent university in 1972 (Broadwater, 2006). Due to the increasing demand for education, the university has opened branches to increase accessibility of its services. George Mason University offers several programs, and it is regarded as one of the top providers of teacher education. The successes that the institution has achieved since its inception would not be possible without a keen focus on its commitment to recruiting and training a competent academic staff. The institution is also cognizant of technological changes that characterize the 21st century. Hereby, measures are put in place to ensure that all members of the teaching staff are offered training opportunities to enable them to acquire skills that are necessary in the 21st century. Furthermore, the teaching staff is allowed flexibility in service provision by use of technology in service delivery (Broadwater, 2006). Infrastructural improvements in the institution include the adoption of modern technologies in the learning process. In fact, such technologies facilitate distance learning that is one of the key strengths of George Mason University. The teaching staff is provided with the necessary material to host virtual classes over technological platforms.

\subsection{Problem Statement and Topic Justification}

Even with its importance among faculty members, the literature review and observations made at the initial stages point to the fact that institutions of higher learning have not fully implemented the training programs aimed at equipping members of the academic staff with the 21 st century skills. It means that the majority of members of their faculty are yet to become effective and efficient in the delivery in the various learning environments where they work. However, as will be seen in the case studies, there are a few universities that have taken advantage of such advancements as those in the technological field to make their programs more relevant and fit into the demands and expectations of the new century.

The current research could not have come at a better time like now. With the advancements in technologies used in education and accumulation of more knowledge, there has been the widening of scope and revision of the curriculum, which has in turn enabled learners to widen their knowledge scope and therefore employability. With the increased level of expectations, faculty members must learn and embrace the use of technology in delivering information to their students and sharing the same among themselves.

\subsection{Research Questions}

The study questions include the following:

- What are the recent trends of the programs of professional development of the academic staff in the 21 st century skills in American universities identified?

- What are the recent trends of the programs of professional development of the academic staff in Maryland and George Mason universities in the 21st century skills?

- What are the methods and media and techniques used to deliver these training programs to the academic staff in Maryland and George Mason universities?

- How do these training programs and methods of delivery for the beneficiary, as practiced in Maryland and George Mason universities, vary with what is the case at King Saud University?

- Taking into account the results of the comparison, what ideas can be proposed for the development of the rehabilitation of academic staff at King Saud University programs?

\section{Literature Review}

\subsection{Defining the 21st Century Learning Skills}

The determination of the skills of learning, as should be the case in the 21st century, is done by Educational Testing Service (ETS). The details are available through its publication, "A Literacy Framework for ICT Literacy" (2007). In the publication, the skills involve competence in collecting and retrieving information, 
organizing and managing information and evaluating the relevance, usefulness and quality of information. The publication also associates the skills with the competence in generating information by using the available resources (AACTE and the Partnership for 21st Century Skills, 2010). The skills that are necessary in the 21st century are those that facilitate learning through the digital age literacy as well as facilitate effective communication and high productivity (Student Development Assessment Team, 2010).

\subsection{Core Subjects and 21st Century Themes}

According to the Elementary and Secondary Education Act (ESEA), core subjects include English, world languages, reading and language arts, science, mathematics and economics among others (Student Development Assessment Team, 2010). Changes that have been introduced in the 21 st century require incorporation of modern competencies and expertise in the main content areas of the learning process. Therefore, such skills include complex problem-solving, critical thinking, communication via multiple media platforms, and collaboration. Student Development Assessment Team (2010) state that the teaching staff plays a key role in facilitating attainment of the skills; thus, it is necessary to find a way of empowering them so that they become more competent in facilitating the learning process. It means that as much as they serve as trainers, the teaching staff must also be subject to regular training processes to increase their competence and relevance in the current and future learning environment. Apart from the academic subject areas, there are a number of interdisciplinary themes that are associated with the 21 st century, and which are equally essential in promoting a clear understanding of the academic content (AACTE and the Partnership for 21st Century Skills, 2010). The themes are global awareness, civic literacy, financial, business and entrepreneurial competence, environmental knowledge and health literacy (Student Development Assessment Team, 2010).

It follows that the level of competence of the academic staff in learning institutions should not only be measured in terms of their knowledge of the core subjects but also by their ability to apply the 21 st century themes in the learning process. Consequently, the teaching staff must undergo regular career development programs in terms of training to impart knowledge of the themes. Thus, such training can be conducted internally with coordination of the management or externally when the management outsources training experts to help boost staff competence (AACTE and the Partnership for 21st Century Skills, 2010).

\subsection{Learning and Innovation Skills}

AACTE and the Partnership for 21st Century Skills (2010) emphasized the need for educators to be assisted to acquire learning and innovation skills. The skills are often mentioned when making reference to the 21 st century skills, and they are regarded as the attributes that differentiate educators who are prepared for more complex work environment that is the characteristic of the 21st century from those who are not (AACTE and the Partnership for 21st Century Skills, 2010). Currently, educators are likely to encounter more challenges in the process of imparting knowledge to students compared to the past decade. Thereafter, they should acquire critical thinking and problem-solving skills, communication, collaboration and ability to demonstrate creativity and innovativeness (Wang, 2014). Critical thinking skills enable teachers to be competent in evaluating evidence and claims so as to effectively solve non-familiar problems in conventional and innovative ways (Gearhart, 2010). Teachers must also refresh their communication skills to be able to apply written and oral skills in different forms and contexts. Collaboration skills are also vital in that they help members of the academic staff to work as a team. Therefore, they are able to consult and devise workable solutions to day-to-day challenges that they face. Teachers must also be ready to create new techniques and worthy ideas that are applicable to different situations that they encounter (Gearhart, 2010).

\subsection{Information, Media and Technology Skills}

The 21st century educators should demonstrate competence in information literacy. For example, they should be capable of critically and competently accessing and evaluating information and managing information flow from a wide variety of sources (AACTE and the Partnership for 21st Century Skills, 2010). It is also vital for them to be trained on media literacy so as to be able to understand the process that takes place in the construction of media messages and the importance of such messages. Due to increased access and usage of various media forms by the 21 st century learners, it is necessary for the teaching staff to be guided on how to use appropriate media creation tools with a close consideration for the conventions involved (Student Development Assessment Team, 2010).

Furthermore, the use of information communication and technology is more pronounced in the current information age such that educators can hardly manage without it. It is worth mentioning that ICT is used as a research tool. It also aids in organization and evaluation of communication information. Thus, learning institutions should show concern about the need to have a competent teaching staff with regard to the use of 
modern ICT skills. It helps them create and disseminate information to learners with much ease and at a faster rate in comparison to the past when all notes and other learning tools had to be printed and issued to learners in hard copies (AACTE and the Partnership for 21st Century Skills, 2010).

\subsection{Life and Career Skills}

Currently, the learning environment is complex to the extent that the teaching staff needs more than content knowledge. There are several situations when teachers need to apply life and career skills for them to effectively navigate the work environment (Gearhart, 2010). Some of the skills that learning institutions should impart to the teaching staff include social and cross-cultural skills, flexibility and adaptability, and initiative and self-direction among others. The world is commonly perceived as a global village owing to the power of technology in the $21 \mathrm{st}$ century (Vaughan, 2013). Thereafter, educators interact and disseminate information to learners from adverse cultural backgrounds. They should have a clear knowledge of the cultural expectations of all learners to make their interactions fruitful (AACTE and the Partnership for 21st Century Skills, 2010).

\subsection{Technological Pedagogical Content Knowledge (TPCK) for Educators}

In addition to the general competence as defined by the P21 framework that is discussed above, it is also important to consider the vital work of AACTE's Committee on the subject of innovation and technology. It involves examining the committee's integration of technology in educator preparation programs. Technological Pedagogical Content TPCK is the framework that provides explanation and description of the knowledge that teaching staff needs to effectively integrate technology in teaching. There is specific subject content that requires a clear understanding and negotiation of pedagogy, technology and content (Gearhart, 2010).

\subsection{What do 21 st Century Educators Need to Know and Do?}

Commitment to realization of the 21st century knowledge skills for all students' entails efforts to support educators so that they can master the competence that facilitates the attainment of positive outcomes for learners. According to Gearhart (2010), the competences are:

* Ability to align instruction with standards with particular attention to the standards that embody the skills and knowledge that are required in the 21 st century.

* The incorporation of technologies into pedagogy and content and demonstration of the ability to apply technologies to meet given learning outcomes.

* Ability to strategically balance direct instruction with project-oriented methods of teaching.

* Application of adolescent development knowledge to the policy of educator preparation and education.

* Active participation in learning communities so as to tap competence and expertise within a school district by means of coaching, team teaching and knowledge sharing.

* Ability to act as peer coaches with other educators.

* Application of various strategies to collaborate with diverse learners and effective creation of learning environments that support differentiated teaching and learning.

* Ability of 21st century educators to embrace career-long learning as part of their professional ethics.

After reaching a consensus on the vision for student outcomes and the determinants of educator competencies, policy formulators and those who hold leadership positions in educator preparation should ensure that their systems, programs and policies are aligned so as to gain a clear understanding of how technologies, pedagogies and content areas relate (AACTE and the Partnership for 21st Century Skills, 2010). Educators should also undergo regular induction processes to facilitate evolution from pre-service. Most importantly, educators should be made to accept the fact that learning should be part of their work ethics so that they need to acquire new skills to remain competent in the 21 st century teaching skills (Gearhart, 2010).

\subsection{How Educator Preparation Programs should respond to the Demands of the 21st Century Learning}

Over a number of years, leaders in the education sector in America have pursued knowledge and skills initiatives that are relevant to the 21 st century learning environment. The most effective initiative is to ensure that the 21 st century knowledge and skills are integrated into the essential education support systems (Gearhart, 2010). Programs should be made to employ the 21st century knowledge and skills in response to the demands of the 21 st century learning. 


\subsection{Leadership}

The program leadership teams are entrusted with the responsibility of setting the stage and leading in the adoption of 21st century teaching and learning (Sharma, 2012). To achieve the objective, the leadership teams should seek to answer questions relating to the most important student outcomes, the way educators can be prepared to produce the desired outcomes, changes one has to introduce to facilitate the attainment of the outcomes among others (Lucas-Alfieri, 2015). Educator preparation is highly interdisciplinary and interdependent. Therefore, success in implementing the 21 st century vision will be achieved if it is made to be part of a university-wide transformation (Gearhart, 2010).

\subsection{Program Design}

Lucas-Alfieri (2015) suggests that one of the most important aspects of the 21st century educator preparation initiative is program re-design. Apparently, state standards, professional teaching standards and accreditation requirements should show the efforts that are made to add some extra layer to the challenging task of integrating skills purposefully into the program and assessments and the instructional models (McKay \& Lenarcic, 2015). An effective educator preparation program should take into account the fundamentals that include coherence, connected clinical experience, school-university partnerships, strong interdisciplinary curriculum and performance-based assessment that is done with close consideration of the professional standards (AACTE and the Partnership for 21st Century Skills, 2010). Furthermore, concerted efforts should be made to integrate 21st century knowledge and skills into the program, while the curriculum should entirely emphasize instructional models that facilitate student development of higher order thinking skills (McKay \& Lenarcic, 2015).

\subsection{Curriculum}

According to AACTE and the Partnership for 21st Century Skills (2010), the curriculum should not be employed as a standardized one-size-fits-all component. Teacher candidates are expected to play a crucial role in content and instruction development and organization for their students due to the changing dynamics of student population and rapid technological advancements (Rummler, 2010). Thus, an effective 21 st century curriculum should be designed in such a way that it facilitates the understanding and application of 21 st century skills in all subject areas (McKay \& Lenarcic, 2015).

\subsection{Instructional Models}

The instructional model requires integration of innovative and research-proven teaching strategies. Modern technologies and real-world resources are also vital elements that should be incorporated in the instructional models. Thereafter, policy formulators should integrate the principles of "teach for understanding", create clinical experiences, establish strong peer mentoring networks and learning communities in addition to critically examining the role played by content, pedagogy and technology in the development of higher order thinking skills (McKay \& Lenarcic, 2015).

\subsection{Learning Environments}

The learning environment in the educator preparation program is a vital component of all system reform initiatives. It is necessary to incorporate structures, strategies and policies that can effectively support the 21 st century knowledge and skills acquisition among educators (McKay \& Lenarcic, 2015). The learning environment should be made in such a way that it provides all necessary learning tools and supports constant acquisition of knowledge for educators (AACTE and the Partnership for 21 st Century Skills, 2010).

In the next chapter, the researchers will then compare how Maryland and George Mason universities have embraced technology in the development of their tutorial staff and that of Saudi Arabia's King Saud University

\section{Methodology}

As an approach, the study utilized qualitative method of research in which the websites of the various universities were examined. The researchers also considered other secondary materials relevant to the study topic, especially the publications by the universities. With the information obtained, the researchers were able to identify the recent trends of the programs of professional development of the academic staff in the 21st century skills in American universities. During the analysis, the information obtained was then put into various themes. Coding, as used in the qualitative research, allowed us assign words and phrases which summarized the information obtained. The method was chosen since it could allow the researchers come up with the recent trends of the programs of professional development of the academic staff in Maryland and George Mason universities in the 21 st century skills. They also introduced the possibility of comparison between the achievements of the two universities with what is the case at King Saud University. 
By going through the websites of the universities, the researchers were able to identify the methods, media and techniques used to deliver the various training programs to the academic staff in Maryland and George Mason universities. Even most importantly, the revelations on how the training programs and methods of delivery for the beneficiary, as practiced in Maryland and George Mason universities, vary with what is the case at King Saud University was very important. The information assisted in emphasizing the benefits of having these programs versus the dangers of not having them. In such a way, it became easy to propose various recommendations for the development of the rehabilitation of academic staff at King Saud University programs.

The researchers were keen on getting the opinions of the members of the faculty as well as some of the employees from the two universities through their various publications and social network forums. Those looking for the information were keen on comments made by those who were directly involved in training programs implemented by the university, especially the electronic ones. Through this, they were able to obtain information regarding the programs and the best ways the stakeholders believed the programs could be enhanced to enable them experience maximum output through improved efficiency and effectiveness. In addition, the researchers were keen to try and secure postings that could lead to the opinions of both those who had been employed for years and the instructors who had just been absorbed for divergent results.

With this approach, the study took into account the opinions of a good number of employees as well as other stakeholders. The researchers simply categorized their information into the various themes identified. The themes then formed the various thematic areas to be addressed under findings and discussions

\section{Findings and Discussions- Comparisons}

The chapter will consider the following areas in its attempt to provide a comparison between how Maryland and George Mason universities have embraced technology in the development of their tutorial staff and that of Saudi Arabia's King Saud University.

Generally, it is acceptable among institutions of higher learning that the development of effective training programs for members of the academic staff is what can enable them equip their workforce with modern information technology and communication skills. Such skills must be able to meet the expectations of the educational requirement in the 21st century's education process. Based on the undisputed significance of training for members of academic staff, most American higher learning institutions have made great strides in advancement of long-term action plans to aid in development of competent human resources.

Some of the training programs that are used to facilitate acquisition of 21 st century professional skills are orientation, general workshops, start of year or semester conferences, customized workshops, consulting and instructional support. Other programs are on-line training, webinars, collaboration and Interaction Services like discussion forum, blogs and wiki among others. Using a comparative approach, the current research discusses the 21st century professional skills training programs as applied in two American Universities; University of Maryland and Georg Mason University in comparison to King Saud University.

\subsection{Start of Academic Year Conferences and Workshops}

Conferences and workshops have increased in terms of popularity in modern times as one of the ways by which learning institutions promote information dissemination. In the programs, personalities who are believed to be authorities based on possession of expertise in various academic and social subjects are invited to give their presentations. University of Maryland is cognizant of the role of conferences and workshops, which is why it organizes programs at the beginning of the academic year or at the start of the semester. The programs present opportunities for faculty members to interact with external professionals and share information in a manner that facilitates professional growth and development. For example, University of Maryland an annual conference that is organized with the sponsorship of Maryland State Department of Education (MSDE) and Maryland Assessment Research Center (MARC) to facilitate information sharing. In 2016, the annual conference was organized on 11th March to facilitate a discussion on Data Analytics and Psychometrics.

Similarly, George Mason University schedules conferences and workshops at the beginning of the academic year or semester. The institution has a debate camp that presents an opportunity for academic staff and students to interact. In George Mason University, the debate camps are organized with an aim of promoting communication and educational activities that offer satisfactory learning experience. The debates are fruitful in faculty development as they give participants an opportunity to listen to and interact with topic experts on vital public policy issues. A part from the academic benefits of the seminars and workshops, they have socializing effect that enables the academic to integrate new students into academia by supporting their engagement in the learning process (American University, Washington D.C., 2016). 
Conference and seminar sessions provide members of the academic staff an opportunity to interact with learners in a free environment outside the class rooms. In such cases, educators learn ways by which they can respond to any forms of misconduct, get a clear understanding of the nature of their learner's talent-wise and behavioral characteristics that may call for an intervention or a corrective measure. Besides, the conferences enable academic staff members to create learning environments for ambiverts, introverts and extroverts and to change their perception on success with respect to the 21 st century changes. The programs also show the institutions' commitment to facilitate social interaction to promote team work and cultural diversity, which is essential, as the world continues to become a global village (American University, Washington D.C., 2016).

Contrary to the University of Maryland and George Mason University, King Saud University has not been keen in organizing seminars and conferences at the start of academic years or semester. Student guide books are distributed to all new enrolled individuals in King Saud University to have them introduced to the institution itself and all that is expected of them during their entire stay within the institution (King Saud University, 2010). Information that is contained in the guide book range from the admission and registration process, E-admissions and registration, academic guidance, procedures to be followed when one needs to differs studies, absences and warnings, examinations and grading among others. The student information guide books are effective in relaying information to students to facilitate their integration into the system. However, the guide books provide a less interactive information dissemination form that does not give faculty members an opportunity to interact with learners. As such, the academic staff does not have enough vital personal information about their students. The program lacks the personal or one-on-one interaction sessions that is associated with conferences and workshops (King Saud University, 2010).

Provision for conferences and workshops at the beginning of the academic year or semester is responsive to changes in 21 st century academic staffs' professional skills development. It is because the programs offer opportunities for knowledge sharing. Currently, success is largely dependent on the ability to share, communicate and apply knowledge in solving complex problems. Success also lies on people's adaptive capacity and their level of innovativeness in response to the ever changing situations and societal expectations. It is currently associated with people's ability to control and enhance the power of technology to facilitate creation of new knowledge (Robinson \& Kay, 2010).

\subsection{General Workshops}

General workshops are organized for continuous interaction and knowledge sharing. Those are vital in the context of the current educational environment that is characterized by new scientific discoveries and innovations. University of Maryland offers general workshops to cater for the need for career development and professional growth of its academic staff.

The conventions are used to enable educators learn the techniques that are usable to promote deep learning with students irrespective of the size of the classes. They usually focus on research, practice, and conversation. For example, on February 11th 2016, the University organized a Joint space sciences workshop that involved physicists, astronomers and astrophysicists NASA's Goddard Space Flight Center and the University of Maryland. Through such workshops, the entity promotes professional development of its academic staff as they are equipped with current information regarding new innovations. The workshop involved a discussion on particle acceleration in the universe and it brought together scientists from around the world to share their observations, theories and collective suggestions on how to react to modern technologies in the 21 st century.

George Mason University also organizes various general workshops to enable its academic staff interact and share professional knowledge. With the help of the University's partners like the National Geographic Society and the National Zoo, it planned and organized the Washington Youth Summit on Environment (WYSE). The summit targeted high school national youth delegates to join the university. The program did not only involve students but also faculty members' participation. The hands-on interactive program promotes student and faculty participation on environmental conservation and sustainability. As such, academic staff members who take part in the program are adequately prepared to deal with or to lead responses to environmental degradation and conservative measures. The aspect of environmental conservation is very vital in the 21 st century due to the implications of hyped innovation tendencies.

\subsection{Customized Workshops}

The University of Maryland is set to host a customized workshop on Orbital Debris and Education Research. The workshop is set to take place on November 17th 2016 with the sponsorship of the Center for Orbital Debris and Education Research. It is aimed at giving an interactive opportunity to leaders from the government, 
academia and industries in a discussion of the needs and state of the art technology, policy and business of the orbital debris enterprise and to explore the concerns of space situational awareness.

George Mason University also facilitates customized workshops with an aim of discussing particular topics. For example, the University organizes the Institute of Forensic that give their faculty members an opportunity to advance and refresh their knowledge on forensics as they listen to presentations that are made by renowned forensic experts. Such workshops are often attended by faculty members of the target subject so that they get specialized information from people who are believed to be experts in the area.

On the other hand, King Saud University does very little in terms of organization of specialized workshops. Despite the fact that the University does not often organize specialized workshops, the institution seems to know the essence of such programs as it had given it a try in 2014. In that year, the University hosted a workshop on IELTS academic module (King Saud University, n.d). Available information on the workshop indicate that the one-day program only focused on IELTS academic test, band scores, sample tests and self-study techniques among others (King Saud University, n.d).

\subsection{Orientation}

The University of Maryland conducts orientation for its new academic staff members. During the process, faculty members are taken through the university organs and informed about various academic and administrative functions. In the University, orientation programs are designed and facilitated by the human resource department with a closed assistance of other departments. Team faculty orientation also assists faculty members in familiarizing themselves with each other so that they are able to work as a team towards meeting the institution's set objectives. The University of Maryland also conducts orientation programs involving the faculty staff and learners. Such initiatives are essential as they provide opportunities for free interaction and familiarization with the work environment. Faculty staff are given an opportunity to ask questions and to seek clarification about anything that can impede performance.

Similarly, George Mason University organizes orientation programs to achieve the familiarization requirement. Orientation is more useful in a work environment where people have different cultural background. Due to unlimited interactions via the internet, faculty members should be trained on how best they can handle challenges that relate to a given employee's cultural valued. It is through this particular activity that faculty members identify themselves as members of a team who have a common goal to achieve.

Orientation also gives new faculty members an opportunity to learn from their colleagues at work. It is important to recruit, train, reward and learn from talented academic staff to ensure that America remains competitive and to facilitate realization of America's dream of equal educational opportunity (American Association of Colleges for Teacher Education, 2008). Education-based changes realized in the 21st century have currently made the role of academic staff more pronounced than it was a decade ago. Presently, teachers are required to acquire a lot of academic growth for all students while at the same time, students' needs are becoming more advanced (Robinson $\&$ Kay, (2010). The role of teachers has never been more important and the teaching process has never been more difficult than it is today. Diversity in learners' needs poses a lot of challenges to teachers such that they require a lot of preparation to succeed in their service delivery.

Despite the role that orientation plays in the familiarization process, King Saud University has not put a lot of weight in conducting orientation.

\subsection{Discussion forum, Blogs, and Wiki}

The University of Maryland has embraced technology in its Faculty training programs. It has training forums, blogs and wiki that are used for training faculty members. The training forums are grouped under CTRL and they play a significant role enabling the academic staff undergo training that involves the take-away topics. As such, the university uses the program to prepare for teaching, to assess learning outcome and how effective the learning outcome is (Center for Teaching, Research, and Learning American University, Washington, DC, 2014).

George Mason University also utilizes discussion forums to promote learning of its faculty members. Discussion forums have proved effective in faculty learning in that it enables members of teaching staff to advance their professional skills without the need to physically sit together in a form of a class set up. On the contrary, King Saud University has not adopted use of these technologies in enhancing faculty program learning. 


\subsection{On-line Training}

Both the university of Maryland and George Mason have also embraced modern technology in the learning process through the adoption distance learning. In the institutions, faculty members have a network-supported learning process. The information technology department and it effectively supports in disseminating information to academic staff members without limitations of time and location. Online learning is intended to eliminate any location based barriers in the learning process. It is achieved through concerted efforts where the IT support groups in the two learning institutions work collaboratively work with faculty in transforming how teaching and learning is undertaken in the institution and to measure the level of expertise for the faculty more so at the time of initiating and implementing new practices in content areas.

Technological adoption in terms of on-line training can also be evidenced in King Saud University. Like the American Universities, King Saud University also offers on-line training programs. An e-learning process was undertaken throughout the institution's operations in 2013, creating an opportunity for training of faculty members (King Saud University, 2013). In the training process, faculty members were taken through training on how to use information technology systems and e-learning instructions. The leadership of the E- Learning programs in the institution are uploaded the success that was realized in the training process whose main intention was to achieve application of virtual classrooms and to give strategies on development of digital content for use in the learning process. Particular areas were singled out for the study and they were relevant because of their ability to boost education environment in the institution (King Saud University, 2013). To ensure success and continues application of the program, the university has established a system to enable its faculty staff to register online for the e-learning (King Saud University, 2013).

Consulting policies and procedures are well established in Virginia Tech University. The institution makes efforts to facilitate consulting by involving externalities based on the belief that such initiatives provide an opportunity for the academic staff to develop professionally besides serving as outreach and communication avenues (Virginia Polytechnic Institute and State University, 2016). The intuition inspires its members of the academic staff to participate in realistic consulting with particular attention to individual's areas of expertise. The entity's members of academic staff are allowed room to do consulting provided that such undertakings do not hinder them from executing their duties and they do not use the institution's resources. In case the consulting undertaking is expected to use the University's resources, a written approval must be obtained from the relevant authorities.

American University provides internal and external training opportunities for its members of academic staff. The internal training is freely offered to the academic staff as evident in the statistical consulting center where staff undergo extensive training on determination of samples among other vital concepts and innovations (American University, Washington D.C., 2016). There is nothing that is in public circulation that confirms that they university offers consulting programs to its staff and the general members of the faculty. However, it has some of its faculty members offering external consulting that are aligned to the institution's policy relating to consulting.

\subsection{Faculty-led Discussion Meeting}

The University of Maryland has discussion meetings led by faculties that are focused on providing various schedules like that for examinations and holydays. A similar program is available in George Mason University to enable communication between the institution's administration and the faculty on issues like examination, accession and student assessment. In a similar fashion, the discussion forums are organized in King Saud University targeting faculty members with an aim of creating a common understanding.

\subsection{Consulting}

University of Maryland and George Mason University both give room for their faculty members to have internal and external consultation processes. They have established policies that allow external consulting as one of the means by which faculty staff enhance their professional competence. The faculty members there are given freedom to get into consulting arrangements provided that such arrangements have a positive impact on their professional development and that they do not hamper their execution of assigned duties. Besides, the institution's consulting policies require that the engagements should not interfere in any way with university resources. On the other hand, it is not clear if consulting training programs are available in King Saud University as there is no information to verify such a statement. The University has some of its faculty members involved in provision of consulting services to other external institutions. 


\subsection{Instructional Support}

The Center for Instructional Development and Education Research (CIDER) offers instructional support to American University's faculty members. It is responsible for organization of professional development events such as workshops and seminar that enable the faculty to access conferences, workshops and other opportunities that are targeted at skills development. They also have study groups and instructional grants for members of the faculty. Those are gathered in such a way that they consider an examination of particular questions for groups regarding teaching and learning. The American Universities offer instructional design services that are facilitated by the institution's e-learning library. The library team has both phone and drop for technical support to faculty on the university's learning management platform (American University, Washington D.C., 2016). The King Saud University does not offer published material to show that it has embraced the application of instructional training in training its members of academic staff.

Other training opportunities include junior faculties training and program summer training. It is through the trainings that junior faculty members acquire practical experience to professional development and learn various classroom techniques. Seminars are also conducted for the juniors more than once every semester. King Saud also provides training and learning opportunities for its junior faculty as evident in the institution's medicine grand round that is given to junior staff. American Universities have program summer training that is done in form of workshops organized and provided by school professional studies. The King Saud University does not have published information to show that it provides program summer trainings.

\section{Conclusion and Recommendation}

Educators play a vital role in shaping the lives and careers of learners. Modernity in the 21 st century has greatly diversified the expectations of the society from educators. For effective growth of a nation, teaching and learning processes should be at their best. It is time when leaders in educator preparation should critically reexamine their roles in 21st century knowledge and skills whose landscape has largely changed. In the paper at hand, efforts have been made to justify the fact that educator preparation programs play a significant role in development of effective engaged academic staff that can improve the outcomes of the education process. Educator preparation leaders in all learning institutions should come together to define and lead the implementation of approaches that support teaching of 21 century knowledge and skills. The transformation is difficult and encompasses expansion of the vision and what it takes to prepare teachers for their roles.

Based on the findings of the study, a number of recommendations can be made to ensure that University's academic staff members are well equipped to be efficient and effective as they help meet the educational requirements of their students in the 21 st century. The suggestions are aimed at helping ensure that faculty members are professionally well equipped to handle the various educational challenges of the modern and technological world. First, there is need for an independent study to establish the various needs of the academic staff in American universities to ensure that the programs being implemented are relevant. Second, educational institutions like King Saud, which are taking slow steps in the utilization of the various instructional technological tools useful in education, should be advised on the importance of incorporating technology. Finally, there will be need for universities to incorporate all their stakeholders in coming up with training programs that are relevant to both the teaching staff and the students.

\section{References}

American Association of Colleges for Teacher Education Committee on Innovation and Technology (Ed.). (2008). Handbook of technological pedagogical content knowledge for educators (TPCK). New York, NY: American Association of Colleges for Teacher Education and Routledge.

American Association of Colleges of Teacher Education and the Partnership for 21 st Century Skills. (2010). 21st century knowledge and skills in educator preparation. Retrieved from http://www.p21.org/storage/documents/aacte_p21_whitepaper2010.pdf

American University (2016). Thank you for attending the teaching, research \& technology workshops on August 17, 18, 23, and 24, 2016. Retrieved from http://www.american.edu/ctrl/teachingandtech.cfm

American University, Washington D.C. (2016). Thank you for attending the 27th annual Ann Ferren conference on teaching, research, and learning. Retrieved from http://www.american.edu/ctrl/conferencesessions.cfm

Broadwater, J. (2006). George Mason: Forgotten founder. Chapel Hill, NC: The University of North Carolina Press. 
Gearhart, D. (Ed.) (2010). Cases on distance delivery and learning outcomes: Emerging trends and programs. Hershey, PA: Information Science Reference. https://doi.org/10.4018/978-1-60566-870-3

King Saud University (2016). Clinical pathology residency program. Retrieved from https://medicine.ksu.edu.sa/en/node/2375

Lucas-Alfieri, D. (2015). Marketing the 21st century library: the time is now. Amsterdam: Chandos Publishing. https://doi.org/10.1016/B978-1-84334-773-6.00005-2

McKay, E., \& Lenarcic, J. (2015). Macro-level learning through massive open online courses (MOOCS): Strategies and predictions for the future. Hershey, PA: Information Science Reference, an imprint of IGI Global. https://doi.org/10.4018/978-1-4666-8324-2

Robinson, S., \& Kay, K. (2010). 21st century knowledge and skills in educator preparation. Retrieved from http://www.p21.org/storage/documents/aacte_p21_whitepaper2010.pdf

Rummler, S. (2010). Collaborative technologies and applications for interactive information design: Emerging trends in user experiences. Hershey, PA: Information Science Reference. https://doi.org/10.4018/978-1-60566-727-0

Sharma, R. (2012). Libraries in the early 21st century: An international perspective. Berlin: De Gruyter Saur. https://doi.org/10.1515/9783110292855

Speck, J. (2010).University of Maryland. Charleston, SC: Arcadia Publishers.

Student Development Assessment Team. (2010). UMD: Integrative learning in the 21st century. Retrieved from http://www.duluth.umn.edu/ dglisczi/Glisczinski/IntegrativeLearningIn21stCentury.pdf

Vaughan, J. (2013).Technological innovation: Perceptions and definitions. Chicago, IL: ALA TechSource.

Wang, V. (2014). Handbook of research on education and technology in a changing society. Hershey, PA: Information Science Reference, an imprint of IGI Global. https://doi.org/10.4018/978-1-4666-6046-5

\section{Copyrights}

Copyright for this article is retained by the author(s), with first publication rights granted to the journal.

This is an open-access article distributed under the terms and conditions of the Creative Commons Attribution license (http://creativecommons.org/licenses/by/4.0/). 